\title{
Happiness and Consumption in Mauritius: An Exploratory Study of Socio-Economic Dimensions, Basic Needs, Luxuries and Personality Traits
}

\author{
Vishal Chandr Jaunky ${ }^{1}$ Jamiil Jeetoo ${ }^{2}$ Shreya Rampersad ${ }^{2}$
}

Published online: 9 October 2019

(C) The Author(s) 2019

\begin{abstract}
Mainstream economics perceive an individual as highly individualistic, presuming that he/ she consumes goods in the most efficient way to optimize his/her level of happiness. This study attempts to explore the nexus between socio-economic dimensions, basic needs, luxuries and personality traits and happiness in Mauritius. Material consumption and happiness are projected to be positively and strongly related. This is usually illuminated in terms of the increased possibilities to satisfy basic needs and luxuries along with other motives which additional spending provides. Other instrumental aspects of consumption, such as its relative, community-based and hedonic magnitudes are accounted. Cross-sectional data are compiled from a household survey with a sample size of 1015 observations. To conduct the analysis, an ordered probit model is applied. The general conclusion is drawn upon the results that socio-economic indicators like educational attainment, residential location, family size, income in addition to the intermediate needs deprivation index, brand consciousness, fashion innovativeness, commercial interest, shopping enjoyment, hedonism, bandwagon effect and personality traits are significantly related to people's happiness.
\end{abstract}

Keywords Consumption · Happiness $\cdot$ Luxuries $\cdot$ Ordered probit $\cdot$ Personality traits

Vishal Chandr Jaunky

vishal.jaunky@ltu.se

Jamiil Jeetoo

jamiil.jeetoo@gmail.com

Shreya Rampersad

shreyarampersad@yahoo.com

1 Department of Business Administration, Technology and Social Sciences, Luleå University

of Technology, 97187 Luleå, Sweden

2 Department of Economics and Statistics, University of Mauritius, Reduit, Mauritius 


\section{Introduction}

Consumer evaluation of happiness is a burgeoning domain of interest, which has sluggishly witnessed remarkable growth over the past decades. In fact, the impact of consumption on happiness has been introduced as a new and hot but imperative domain of concern for economists, psychologists, sociologists and diverse policy-makers over the world. Mauritius is an open upper-middle economy where private consumption has been constantly on the rise. As per the World Happiness Report (2018) which grades countries subjected to happiness on cognizance of society, employment, health and politics, Mauritius bagged the 55th position with a score of 5.891 on 10 and was accredited as the topped the list in Africa.

Assuming that individuals are rational decision-makers, who are fully conscious of their needs and wants given their limited budget, they experience pleasure through their consumption. The economic rationale stipulates that the folks' preferences as consumers are literally anticipated beforehand by themselves (Helliwell et al. 2012). The relative lack of research on the relationship between consumption and happiness is surprising, given that economic theory suggests that the most relevant measure of utility, or satisfaction, is consumption, rather than income. The subjective well-being (SWB) literature has frequently drawn on the concept of needs to explain the flattening out of the relationship between income and SWB after a certain income threshold (Di Tella et al. 2010).

Luxury consumption is a multi-layered behavioural concept, generated by an array of determinants (Kastanakis and Balabanis 2014). In the modern climate where economic uncertainty and unwarranted consumption have become the norm of the day, the happiness of an individual is of key concern (Seinauskiene et al. 2015). Uncovering the causes and their relationships with individual happiness has found new beacon light in the realm of economics, with both the magnitude and complexity of the literature escalating exponentially (Clark et al. 2006). Most people agree that societies should foster the happiness of their citizens. The U.S. Founding Fathers recognized the inalienable right to the pursuit of happiness. British philosophers talked about the greatest good for the greatest number. Bhutan has famously adopted the goal of Gross National Happiness (GNH) rather than Gross National Product (GNP). China champions a harmonious society.

This study examines the impact of consumption and a gamut of personality trait factors on happiness, using primary data, in the Mauritian framework. To the best of our knowledge, this is the first paper which has been undertaken to contribute to the economics literature on happiness studies in an upper-middle African income country like Mauritius by unravelling the impact of an ensemble of socio-economic factors, basic needs indicator, motives and personality traits on happiness. The organization of this paper is as follows: Sects. 2 and 3 provides a review of the relevant literature encompassing conceptual framework, theories and empirical evidences. Sections 4 and 5 discusses research-related details in terms of methodology and data collection. Section 6 presents the results. Finally, Sect. 7 concludes the paper. 


\section{Theoretical Framework}

\subsection{Concept of Happiness}

The concept of happiness has been an elaborate and imperative focal point in psychology and straddles across many other disciplines. Nevertheless, since the last few decades happiness research has become quite a head-turner for economists for reasons such as economic policy, the impact of institutional conditions and to comprehend SWB (Frey and Stutzer 2002). Following the social indicators development, happiness has been broadly extended to social welfare surveys and has become much of a cited topic in the psychological domain and in medical studies (Stanca and Veenhoven 2015a, b).

Former research has otherwise used "ife satisfaction", "subjective well-being", "affect" and "happiness" as comparable terms. A large body of literature has treated SWB instead of happiness which can be encapsulated in large surveys (Frey and Stutzer 2002). However, it is noteworthy that SWB is an amalgamation of three constituents: life satisfaction, the presence of positive mood and the absence of negative mood, together translated as in a single concept called happiness (Ryan and Deci 2001). Furthermore, happiness can be quantified in a rational manner, thereby denoting adequate reliability to be able to compare means in a time-dimension or a country-dimension framework or to utilise regression analysis in order to explore the determinants inducing personal happiness (Krueger and Schkade 2008).

On the other hand, Dutt (2006) postulates that consumption relates to the "driving force of the economy, providing people with the incentive to expend their time and energy to obtain more and better things". Consumption is viewed as the impetus of the economy, the prime purpose that pushes our efforts systematically, rewarding happiness to consumers but having other rippling effects on the community and the society altogether. With this in mind, our productive economy seeks that we make consumption our mode of living and the purchase and use of goods into rituals (Lebow 1955). Classical economic theory would highlight that consumers consume to maximize their utility (satisfaction), but some authors have attempted to dig further into the theory of consumerism to better understand the concept (Dutt 2006; Busch 2008). Fundamentally, the consumer has been portrayed as having to choose between the consumption of two goods, for instance consumption and leisure and between consumption at several points in time. The general assumption was drawn upon the fact that higher consumption yields better results for the individual consumer to attain utility. In fact, according to the majority of economists, the objective of economic activity is usually to reach efficiency so as to optimize the value of production, thereby highlighting the importance of consumption across societies (Dutt 2006).

\subsection{The Relationship Between Happiness and Consumption}

A plethora of studies has concentrated principally on the relationship between income and happiness. Findings from these studies are ambivalent and contrastingly interesting country-wise. The neoclassical economic justification underlines a positive relationship income and SWB or happiness because higher income propels more consumption (Noll and Weick 2010). Economists have strongly debated that consumption is a better indicator of happiness than income and the latter is most probably a "noisy proxy" (Meyer and Sullivan 
2003). Yet, traditional economists have barely shown their interest to uncover the effects of consumption on happiness (Stanca and Veenhoven 2015a, b).

Not surprisingly, most studies have focused on the developed, affluent and industrialized countries to explore the relationship between happiness and consumption such as United States, Germany and China (Deleire and Kalil 2010; Headey et al. 2008; Noll and Weick 2015). The connection between happiness and consumption expenditure is of great interest to a developing country like Mauritius because over the last 50 years, the consumption patterns have altered drastically due to demographic changes and dynamic lifestyles. As a matter of fact, the absolute level of consumption influences the level of happiness. This hypothesis signals a direct positive relationship consumption and well-being and also denotes the notion of "insatiable consumer" (Guillen-Royo 2007). However, there was a paradigm shift with the trend when it was asked whether happiness influences consumption instead. The consumption behaviour of happy persons deviated from those unhappy. Happy people tend to save more and spend less compared to the latter, with respect to their future decisions and expectations (Guven 2009). Before proceeding further, it would be appealing to analyze consumption as a multi-faceted concept and its influence on the personal happiness of an average citizen.

Coupled with the above, necessity is one basic reason behind consumption; biological needs for food, water and shelter must be met (Busch 2008). On a general note, the link between income and SWB has been stronger for the poor, implying that the latter spend extensively on food, housing and basic services (Guillen-Royo 2008). With this in mind, Maslow's Hierarchy of Needs can be considered whereby human needs are categorized into five planes. The Maslow's Pyramid of Human Needs' theory postulates that people move upwards to fulfill their needs towards self-actualization. Basic goals are correlated to each other, translating into that when a need is moderately satisfied, immediately a higher need arises to govern the conscious mind and to convey sense gratification (Maslow 1943). Through the hierarchy of needs, the happiness of poor consumers will soar with each improvement in their consumption when the latter is a projection of swelling material levels. However, once their basic needs are met, additional increases in wealth will not further lead to excess happiness (Caldas 2010).

Consumerism takes its toll when it exceeds our needs and basic level of consumption. Subsequently, the consumer culture has become rampant in our daily routine and the academic economics literature. During the Second Industrial Revolution in Britain, Veblen (1899) devised the term "conspicuous consumption" to refer to the extravagant expenditure on goods and services primarily acquired for the intent of showcasing income or wealth. Albeit the regular use of this terminology in the literature of the demonstration effect, "conspicuous consumption" essentially refers to those consumers who purchase costly and flashy items to display wealth and income. It was put forth that this type of consumption acts as a status signal, however depending on the context.

It has been arguably put on ground that relative consumption holds more importance than absolute consumption. Relative consumption has been defined as "the perceived level and quality of one's consumption relative to that of significant others" including family, friends and the common citizen and therefore accentuates the relevance of social comparison (Noll and Weick 2010). Assessing how much one consumes compared to other stakeholders of the society has prevalently been a crucial determinant in molding a household's expenditure decisions (Kamakura and Du Yuxing 2011). In a similar vein, the concept of "demonstration effect" was used to elucidate on how a household's expenditure pattern may be subjective to the acquisitions of its neighbours. Often, the purchase of goods by others works as a publicity mechanism and may inspire people to raise their consumption, 
thence putting forth that higher expenditure is spurred by higher standard of living and greater social status. On a general basis, consumption is amplified by emulating others and the utility derived will rest upon on what others consume (Duesenberry 1949; Dutt 2006).

\subsection{Socio-Demographic Variables}

Age is an important variable when it comes to determining happiness. The Scientific American postulates an interesting article where Schrock Simring (2013) advocates that a study of numerous targeted Americans born between 1885 and 1980 disclose that happiness increases with age. In fact, the link between age and happiness tends to be U-shaped (Gerdtham and Johannesson 1997). Regarding gender, there is no pre-specific hypothesis about the direct impact of gender on happiness. Therefore the aggregate effect is claimed to be indeterminate on a priori grounds (Gerdtham et al 1999). Education is an important variable in the sense that as expected, educated people experienced heightened happiness. Education is surmised to increase the range of goods to be enjoyed, including stimulating and pleasurable activities, and to be informed about the type of consumer goods apt for good health status. As a cardinal predictor of happiness, location can be classified into rural-based and urban-based. People living in rural areas are happier than those residing in urban regions. Since there is no a priori hypothesis about the straight effect of regional location on happiness, the aggregate effect is therefore indeterminate on the foundation of the theory.

Consistent with the literature, higher levels of household income tend to have strong positive influences on life satisfaction or happiness (Petrunyk and Pfeifer 2016). Most studies posit a small and modest, yet measurable correlation between income and happiness (Schyns 2003; Ahuvia 2008; Diener and Biswas-Diener 2002). One of the catalysts related to this aspect has been contributed by Easterlin (1974). In fact Easterlin's (1974) classic paper dissented over the fact that the differences in income between the "haves" and "havenots" countries are vast but the disparities in happiness tend to slim down. Family size refers to the number of members present in a family. Some interesting articles have postulated that large families tend to be happier because the degree of selfishness may be lower. Kasser (2002) claims that spending more quality time with family, friends and community, fosters happiness rather than money pursuits. Furthermore, civil status is hypothesized to affect happiness. Accordingly, married individuals tend to be happier with their lives while divorced persons tend to be less happy (Di Tella et al. 2003). As a measure of civil status, it is expected that being single (not married or cohabitating) has a negative impact on happiness.

\subsection{Big-Five Personality Traits}

Unsurprisingly, personality factors tend to play an instrumental role in the phenomenon of happiness. In retrospect, a silent revolution has been shaping in personality psychology. The hunt for a scientifically gripping taxonomy of personality factors had begun in the 1970s but its sources can be traced back to the era of Aristotle (Goldberg 1992). Accordingly, early explorers in the sphere, Borgatta (1964, 1969), Goldberg (1981) revealed similar five structures in their lines of research. Later on, the "BigFive" factors had been categorized into the following: Factor I; Extraversion; Factor II, Neuroticism; Factor III, Agreeableness; Factor IV, Conscientiousness and Factor 
Table 1 The big five personality aspects

\begin{tabular}{lll}
\hline 1 & Extraversion & Enthusiasm, zeal, assertiveness \\
2 & Neuroticism & Anxiety, envy, moodiness, frustration \\
3 & Agreeableness & Warmth, optimism, tact \\
4 & Conscientiousness & Vigilance, efficiency, sense of organization \\
5 & Openness & Sensitivity, inclination for variety, fantasy \\
\hline
\end{tabular}

$\mathrm{V}$, Culture. However, Factor V has been newly reinterpreted as Intellect (Digman and Takemoto-Chock 1981; Peabody and Goldberg 1989) and replaced by Openness-toexperience (McCrae and Costa 1987).

Extraversion reflects personality traits such as aspiration, enthusiasm and sensationseeking. Extraverts will thus tend to be happier than introverts. Agreeableness relates to affection, empathy and compassion. Neuroticism is defined by characteristics such as negative emotions, stress and anxiety. Neurotic individuals tend to be unhappy Agreeable individuals are caring and maintain a harmonious relationship with others. So they will be happier than their disagreeable peers. Conscientiousness relates to level of responsibility and planning behaviour. Highly conscientious individuals are rigorously well-organized and prepared. They tend to be successful in their endeavours and this brings on both material (e.g. income) and psychological (e.g. self-belief) rewards which contribute positively to happiness (Soto 2015). Open-to-experience individuals have high levels of intellectual curiosity and imagination. They can develop flashy and eccentric behaviour. As such an opened personality's impact on happiness can be indeterminate.

The Big-Five is an account of the trait concept, which has been the overriding example in the European personality psychology, while its assumptions have been embraced by many scholars to seek consistent and persistent individual differences (Thomae 1989; McCrae and John 1992). Several authors including Goldberg (1983) and John (1989) have asked why the inclusion of five factors only. Yet, it becomes fundamental to study whether five factors are adequate to predict happiness level, albeit often disregarded as a core component in predicting human behaviour (Endler and Rosenstein 1997). Based on the various findings and protagonists of the big five personality model, the framework is a sympathetic attempt to classify the individual differences as tabulated below (Table 1).

\subsection{Other Variables}

\subsubsection{Social Comparison}

The Easterlin paradox is sometimes construed by assuming that after satisfying basic needs, the impulse behind the link between income and happiness is owing to the relative position the income spread. In general, people will compare themselves to those with whom they interact (Festinger 1954). The theory posits a negative relationship between happiness and social comparison due to the influence of negative motives and not to the type of goal. Succinctly, people wish to purchase luxury products to impress others with the desired status ascribed to the luxurious items (Husic and Cicic 2009). Along the same line, social comparisons are withheld on the grounds of conspicuous consumption which demonstrates wealth and status (Linssen et al. 2010). 


\subsubsection{Social Positioning}

Fairly important to the Mauritian diaspora, social positioning refers to the position of a person in the society and this bears closer links to status rather to promote happiness. Various explanations have been provided for the link between social positioning and happiness. A group of people to whom consuming would "make a difference" in a subtle but dissimilar way can be viewed as a symbolic exhibition of social position (Schroder 2013). Additionally, social and religious expenditures are consumption classifications pre-exceedingly used for displaying individual position in the social hierarchy (Linssen et al. 2010).

\subsubsection{Intermediate Needs Deprivation Index (INDI)}

The Intermediate Needs Deprivation Index (INDI) was engendered from Doyal and Gough's (1991) Theory of Human Need (THN) which provides philosophical enlightenment for the identification of health and self-sufficiency as basic needs. These are attained through the fulfillment of intermediate needs such as sufficient food and water, health care, important primary relationships, safe birth control and suitable level of education. INDI, which represents a total indicator of unsatisfied needs at the household stage, is a measure of basic needs (McGregor et al. 2006). As the index increases, this would designate that a particular household does not gain access to more intermediate needs (Guillen-Royo et al. 2013a).

\subsubsection{Monthly Household Basic Expenditure}

Studies portray a positive picture basic expenditure and happiness. Household expenditure accommodates for all basic consumption accompanied by a few additional objects to render expenditure more analogous across households. However, the relative dimensions of consumption cripplingly matter too. A proxy for relative consumption is given by relative expenditure which refers to personal expenditure compared to the expenditure of an independent reference group (Linssen et al. 2010; Wang et al. 2015). Relative concerns may yield an adverse relationship between inequality and happiness (Hopkins 2008).

\subsubsection{Aesthetic Appeal}

Currently, it has become a common sight for people to turn up at shopping malls in most of the developed world, particularly in Mauritius. According to Penalosa, these public spaces grant people different kinds of experiences that ultimately yield to higher satisfaction, "almost happiness itself" (Gilovich et al. 2015).

\subsubsection{Brand Consciousness}

Despite the fact that the relationship between brand consciousness and happiness has scarcely received any attention in the literary journals, brand consciousness can be further extended to brand loyalty and brand attachment. The inclination towards materialism can negatively influence life satisfaction (Kashdan and Breen 2007). Actually, the focus on expensive brands is prompted by the need of feeling better and fuelling self-esteem (Seinauskiene et al. 2015). Similarly, Dunn and Hoegg (2014) uncovered that heavy attachment with brands may be attributed to the feeling of fear. 


\subsubsection{Fashion Innovativeness}

Theoretically a positive link between fashion innovativeness and happiness has been noted. Goldsmith and Hofacker (1991) conjectured that innovativeness should concentrate on particular products. Fashion innovativeness can be widely regarded as higher income, greater level of education, younger in age and more risk-loving attitude.

\subsubsection{Advertising or Commercial Interest}

Commercial interest can be understood as customers having their own outlook towards the products being advertised (Hosein 2012) and is one of the most influential factors on customers purchase intention (Karthikeyan and Balamurugan 2012). According to Popescu et al. (2010), commercial interest plays an instrumental role in creating needs, so that supply generates its own demand. This is consistent with Say's law. From this perspective, the increase of consumption is negatively associated with happiness because individuals purchase things which may not be essential and do not tally entirely to their needs under marketing density. In a similar vein, with higher exposure to advertisements through billboards, television or newspapers, individuals may engage in impulsive buying on credit terms, very often occasioning debt inflation (Popescu et al. 2010). In his investigation of the affluent society, John Kenneth Galbraith contested that advertising generates wants for the population, stimulating them to consume more without rendering them better-off (Dutt 2008).

\subsubsection{Shopping Enjoyment}

Commonly, people who enjoy shopping experience higher levels of happiness (Oropesa 1995). It is highlighted that recreational shopping is a way of escapism from unsatisfied emotional needs. Lasch (1991) advocates that shopping enjoyment is "a therapeutic activity that seeks to reestablish wholeness and well-being in society".

\subsubsection{Hedonism}

The word "hedonism" pertains to pleasure or fun. Hedonism is another key element in measuring happiness. It could be argued that deriving pleasure, entertainment and amusement is an inner feeling of the person, that is usually genuine and gratifying (Guillen-Royo 2008). As noted by Campbell (1998), this theory of consumerism is inner-directed. It does not presume that consumption behaviour is either guided by, or oriented to, the actions of others. In that sense, it breaks with the long-standing sociological tradition that presents consumption as an essentially social practice. On the other hand, this theory does not present consumption as driven by material considerations.

\subsubsection{Bandwagon Effect}

Popularly known as the "cromo effect", the bandwagon effect is a phenomenon often witnessed in the realm of microeconomics. Well-documented in behavioural science, it exemplifies the desire of individuals to buy a product in order to conform to the people they wish to be allied with, to be fashionable or trendy (Leibenstein 1950). Having 


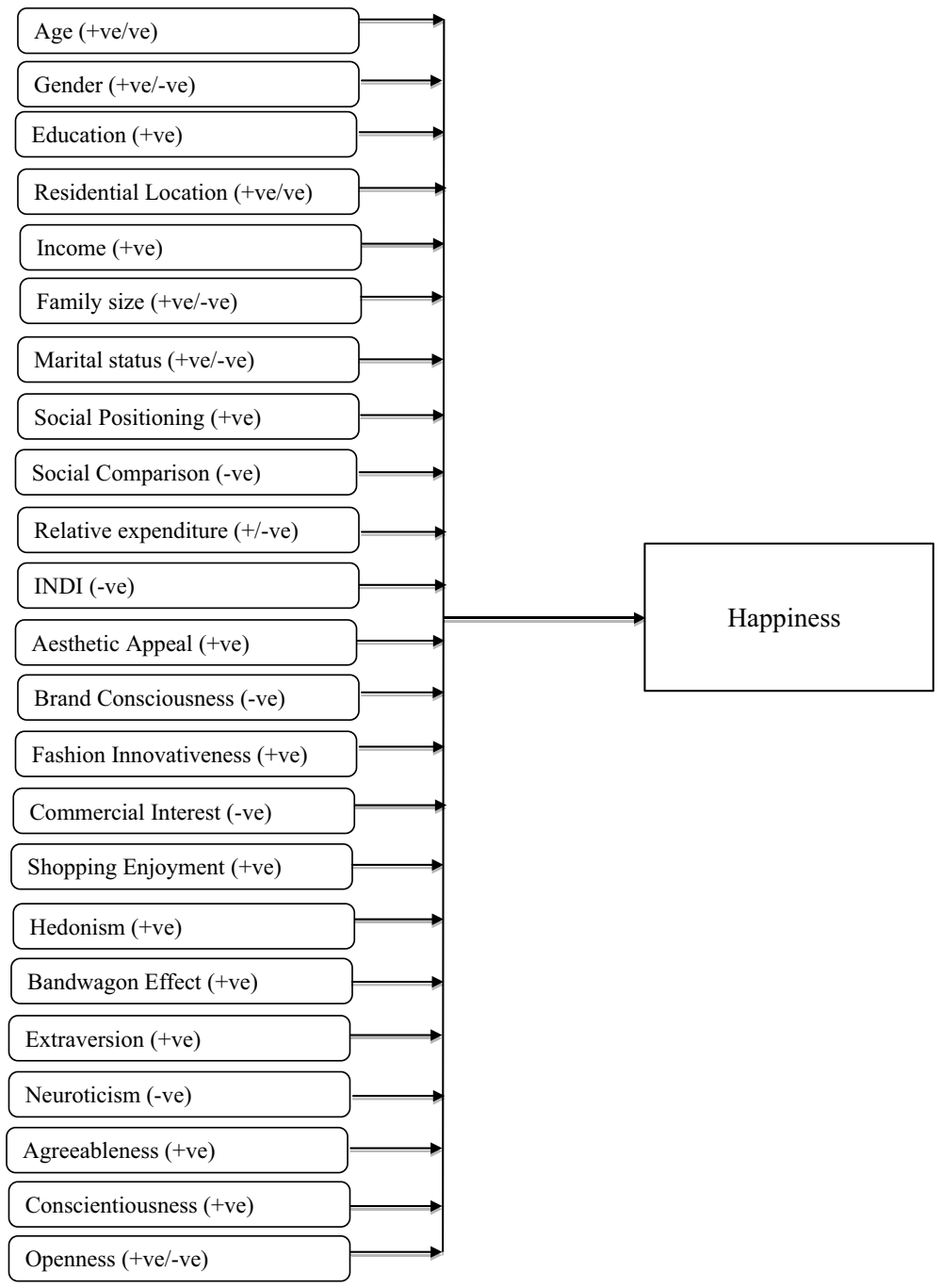

Fig. 1 Hypothesized relationships

broad implications in the fields of consumer behavior, it prevails. In overall sense, individuals who want to associate themselves with the mass, intensify their consumption of a particular commodity as others are consuming it. The theory posits a positive association between happiness and bandwagon effect (Knight and Gunatilaka 2009).

\subsection{Conceptual Framework and the Expected Signs}

The illustration below is an overview of the different hypotheses pertinent to the concept of individual happiness. A cloud of variables has been taken into consideration. Arguably, subjective appraisals cannot be paralleled between individuals. Different scales for happiness vary from one person to another. Each of the variables is outlines in Fig. 1. 


\section{Brief Literature Review}

Previous studies on happiness and consumption have been conducted. Different empirical studies employing macro and micro data for several economies formed a consensus that a rise in per capita income does not translate into happiness directly. For instance, GuillenRoyo (2008) propounded that in the field of material poverty consumption and happiness are anticipated to be positively related. In her aptitude, several covariates were used such as age, gender, religion, cohabitating, chronic illness, self-employed, homemaker, Intermediate Needs Deprivation Index (INDI), log of total expenditure, average expenditure, relative expenditure, basic needs motives, hedonic motives, social interaction and type of site. The study was undertaken to analyse the repercussion of expenditure and motives in the corridor of Peru. To embark on the study, data was extracted from the 2004 Resources and Needs Questionnaire on a sample of 1000 households in order to capture miscellany in Peru. An Ordered Probit model was specifically used and it was accomplished through Maximum Likelihood.

Similar studies were conducted in less fortunate countries like Thailand (Guillen-Royo 2007) using the Ordered Probit model for discrete alternatives. The significance of the motive variables stresses on the fact that they encapsulate personality traits. Similarly, Guillen-Royo et al. (2013a, b) employed data from 2002 to 2007 in Bangladesh and Thailand reported that universal and local goals should be given importance homogeneously to get a better gist of people's happiness. Socio-economic variables and the measure of need satisfaction play critical role in addressing goal satisfaction in Bangladesh and Thailand. Other literatures bear testimony to the heterogeneous impacts of consumption on happiness. Quintessentially, Wang et al. (2015) have employed panel data for the sake of modelling to curtail the effect of unnoticed time-invariant individual characteristics. The association between aggregate consumption expenditure and happiness was tested through pooled OLS and fixed effects regressions, yielding a significant and positive relationship. Similar outcomes match the consistency with Noll and Weick's (2015) panel results in the case of Germany.

\section{Methodology}

The methodology aims at estimating the happiness function with an inflated set of socio-economic variables, basic needs, consumption-induced motives and personality factors. About the model specification, former research has variably used Ordinary Least Squares (OLS), ordered logit or ordered probit to measure happiness. A clear distinction is made between linear and non-linear data cross-sectional data models. Standard econometric technique such as OLS method for statistical regressions can be considered to ensure that the findings are of statistical significance. Several prior studies have considered the use of OLS approach (GuillenRoyo et al. 2013a, b). However, with the endogenous variable being categorical and discrete, the OLS method ceases to generate the best linear unbiased estimator (BLUE). In fact, the dependent variable is presumed to be cardinal whilst using OLS. Upon the violation of such a key assumption, anomalies may crop up, such as spurious predictions outside the scale. In line with that, invalid hypothesis testing may stem with regard to the coefficients of the independent variables and the regression line, leaning on wrong sampling variances and inconsistently standard errors. Subsequently, the measure of goodness of fit known as $R^{2}$ may prove to be 
ambiguous (Peel et al. 1998). Additionally, the non-linearity element results in the intricacy to showcase the output. As a better alternative for the modelling of categorical and ordinal data in the realm of economics, the ordered probit approach is applied.

The ordered probit model uses maximum functions and hinges on "normal" probability distribution and considers mapping of the latent scale to the response groups is done by making use of continuous cut-points. The categorical dependent variable displaying ordered multinomial results relating to perception comprise of "not very happy", "fairly happy" and "very happy" given by:

$$
y_{i}=j \quad \mu_{j-1}<y_{i}^{*}<\mu_{j}, \quad j=1,2 \ldots, m,
$$

where the latent variable $y^{*}$ is considered to be a linear function of a vector of variables $x$, adding a random error $\varepsilon$ :

$$
y_{i}^{*}=x_{i}^{\prime} \beta+\varepsilon_{i} \quad \varepsilon_{i} \sim N(0,1),
$$

where $\dot{x}_{I}$ represents the independent covariates which interpret the level of happiness $\beta$.

Note that $y *$ is unobserved. What is observable is:

$$
\begin{aligned}
y & =0 \text { if } y * \leq 0 \\
& =1 \text { if } 0<y * \leq \mu_{1} \\
& =2 \text { if } \mu_{1}<y * \leq \mu_{2} \\
& \cdots \cdots \\
& =J \text { if } y * \geq \mu_{J-1}
\end{aligned}
$$

The $\mu$ 's are unknown threshold parameters to be estimated with $\beta$. Thresholds parameters determine the estimations for different observed value of $y$. These threshold parameters can be interpreted as intercepts in Eq. (2). For all the probabilities to be positive, then,

$$
0<\mu_{1}<\mu_{2}<\ldots \ldots \mu_{j}, \quad j=1,2 \ldots, m
$$

The following probabilities are formulated:

$$
\begin{aligned}
& \operatorname{Pr}(y=0 \mid x)=\Phi\left(-x^{\prime} \beta\right) \\
& \operatorname{Pr}(y=1 \mid x)=\Phi\left(\mu_{1}-x^{\prime} \beta\right)-\Phi\left(-x^{\prime} \beta\right) \\
& \operatorname{Pr}(y=2 \mid x)=1-\Phi\left(\mu_{2}-x^{\prime} \beta\right)
\end{aligned}
$$

For these probabilities, the corresponding marginal effects of the changes in the independent variables are:

$$
\begin{aligned}
& \frac{\partial \operatorname{Pr}(y=0 \mid x)}{\partial x}=\Phi\left(-x^{\prime} \beta\right) \beta \\
& \frac{\partial \operatorname{Pr}(y=1 \mid x)}{\partial x}=\left[\Phi\left(-x^{\prime} \beta\right)-\Phi\left(\mu_{1}-x^{\prime} \beta\right)\right] \beta \\
& \frac{\partial \operatorname{Pr}(y=2 \mid x)}{\partial x}=\Phi\left(\mu_{2}-x^{\prime} \beta\right) \beta
\end{aligned}
$$


The analytical framework as presented above is applied to the survey data discussed in Sect. 5 to identify the main determinants of perceived happiness. The findings on these equations are deferred in Sects. 6 and 7.

\section{Data}

A household drop-off survey was conducted and this type of survey usually guarantees a high response rate. The process of data collection initiated in the last week of January 2016 and concluded in the second week of March 2016. All in all, the assemblage of primary data lasted approximately 3 months. Using random sampling method, it is notable that an aggregate of 1300 questionnaire $^{1}$ was disseminated to an array of companies, schools, factories, shopping malls and homes across the country. The chosen companies are situated in various business parks, such as Ebene Way, Orange Tower, Kendra Commercial Centre and Bagatelle Shopping Mall whilst household visits were constantly made throughout Mauritius, in areas like Quartier Militaire, Flacq, Goodlands, Triolet, Rose Belle, Candos, Montagne Blanche, Reduit, Port Louis, Beau-Bassin, Rose-Hill, Vacoas, Phoenix, QuatreBornes and Curepipe. However, due to incompleteness, inadequateness and bias issues, 285 questionnaires were cast-off from the 1300 collected. A final sample of 1015 questionnaires was yielded. It is noteworthy that since the ordered probit model calls for huge datasets, a high response rate is a prerequisite in order to validate the reliability of the results. Kanuk and Berenson (1975) advance that the accuracy of a survey depends on the immensity of the response rate. Put differently, a good survey practice includes omission of the non-response rate and other errors. Babbie (1973) advocates a 50\% response rate as an appropriate threshold with more to be better so as to mark the survey reliable and effective.

First of all, the subjects were required to answer the questions based on their impressions on personal happiness and consumption factors. The questionnaire considered for the study being undertaken consists of a database of questions which are segregated into six distinct sections. Each segment is a prerequisite to the study as the questionnaire was designed to adapt to the rudiments of the econometric modelling. Then, the inclusion of a perception profile was essential to construct a five-point psychometric scale in an attempt to create indices previously scarcely explored in academics and the field of happiness.

To elucidate further, below is a description of the survey put at the disposal of the public to collect data. Section A: Socio-demographic profile consists of age, gender, working place, educational completion, regional location, monthly income category, family size and civil status. Section B pertains to the social dimensions based on a five-point Likert measure: "Strongly Disagree", "Disagree", "Neither Agree nor Disagree", "Agree" and "Strongly Agree" to capture Social Comparison and Social Positioning. Section C relates the happiness measure of the respondent in terms of life in general. Section D represents an extension of basic considerations. The question pertaining to household expenditure was kept open-ended and quantitative to capture total monthly household expenditure on basic needs and intermediate needs deprivation index. Section E sheds light upon luxury consumption and other related motives which were hinged with a five-point Likert type scale: "Strongly Disagree", "Disagree", "Neither Agree nor Disagree", "Agree" and "Strongly Agree" to capture Aesthetic Appeal, Brand Consciousness, Fashion Innovativeness,

${ }^{1}$ The questionnaire is available upon authors' request. 
Table 2 Summary of the dependent variable, happiness

\begin{tabular}{lcll}
\hline Happiness & Frequency & Percentage & Cumulative \\
\hline 1. Not very happy & 88 & 8.67 & 8.67 \\
2. Fairly happy & 477 & 47 & 55.67 \\
3. Very happy & 450 & 44.33 & 100 \\
Total & 1015 & 100 & - \\
\hline
\end{tabular}

Commercial Interest, Shopping Enjoyment, Hedonism and Bandwagon Effect. Section F draws attention to the personality traits profile of the respondent where a five-point Likerttype scale was constructed tagging "Strongly Disagree", "Disagree", "Neither Agree nor Disagree", "Agree" and "Strongly Agree". It is therefore expected to collect information relevant to the characteristics of human behaviour. The statements are based on a study done in Mauritius by Jaunky and Ramchurn (2014).

As specified formerly, the dependent variable, "happiness", is substantiated from the statement: "life in general" The responses are built on three-point Likert-type rule whereby 1 stands for "Not Very Happy", 2 for "Fairly Happy" and 3 for "Very Happy". This is a technique to attenuate variation in the responses to furnish more efficient and consistent estimates. Table 2 below illustrates a summary of the endogenous variable.

Conspicuously, only $8.67 \%$ of the 1015 participants handpicked a rating of 1 whilst $44.33 \%$ selected a score of 3 . The rest of the $47 \%$ chose an evaluation of 2 . The category of "Not Very Happy", if not unhappiness, is thinly populated. The main covariates pertaining to socio-demographics are as follows: age, gender, education, residential location, income, family size, civil status. Dummies were generated for each of the variables except for age and family size. The fact that fewer respondents have reported 'primary' qualification is not right to report these observations this way. However, omitting them is unethical. They are included in the dataset as the minimum requirement to avoid conflicts.

The Indicator Needs Deprivation Index (INDI) was adapted to the actual research context from prior studies (Guillen-Royo 2007, 2008; Guillen-Royo et al. 2013a, b) that instrumented it directly from McGregor et al. (2007). Serving as a barometer for basics, it indicates unquenched needs at the household level. Slightly transmuted, the eight statements related to food, access to gas, water, electricity, medical treatment, harmless birth control, primary relationships and education. Based on Desai and Shah's (1988) approach, an index (mean) was constructed as given: INDI $=\sum$ Scores/8. Therefore, an index of 1 or closer would insinuate that a Mauritian household does not access to any of those basic facilities while an index closer to 0 would imply a brighter picture of having access to almost of them.

Also, the Hedonism Index $=\sum$ Scores/2. Likewise, some further indices were generated to capture personality traits corresponding to the individual happiness. Since the Big-Five is largely reckoned in various previous works (Costa and McCrae 1992), survey respondents were instructed to rate how they strongly agree or dissent with the statements on a five-point Likert-type scale, whereby a score of 1 is synonymous to "Strongly Disagree" and a score of 5 would signify "Strongly Agree". Along the same line, the CSR (Corporate Social Responsibility) Report spearheaded by Kenexa Research Institute (2007) contributed in developing the five indices. Three questions are forwarded to capture each personality trait and afterwards used to generate the indices. The figure below shows the formula used to generate the five dimensions of personality such that the Extraversion Index $=\sum$ Scores $/ 3$, Conscientiousness Index $=\sum$ Scores $/ 3$, Neuroticism Index $=\sum$ Scores $/ 3$, 
Openness Index $=\sum$ Scores/3, Agreeableness Index $=\sum$ Scores/3. The summary statistics of the variables used for the ordered probit model are shown in Table 3. "Appendix" describes how the various variables are constructed from the questionnaire.

\section{Findings}

Preliminary diagnostic tests reveal a variance inflation factor (VIF) of 1.88 which is less than 5. There is no evidence of severe multicollinearity. The White test of heteroskedasticity is computed to be $\chi^{2}(454)=728.46$ [ $p$ value $\left.=0.000\right]$, which implies the rejection of the null hypothesis of homoskedasticity. Robust standard errors will be considered. The Skewness/Kurtosis test for normality is $\chi^{2}(5984)=29,792.894$ [ $p$ value $\left.=0.000\right]$. Moreover, the Shapiro-Wilk tests show presence of non-normality with a $z$-statistics of 6.207 [ $p$ value $=$ 0.000 ] by residuals. These tests are very sensitive to departures from normality with large sample sizes are involved and such departures are of little importance (Goldsmith 2016). This supports the non-consideration of the OLS method. The Ramsey Regression Specification Error Test $($ RESET) statistic is $\mathrm{F}(3,983)=0.39$ [ $p$ value $=0.758]$. The null that the model has no omitted variables cannot be rejected. The model is thus well-specified.

Table 4 depicts the estimated results and the respective marginal effects under the ordered probit model. The Chi square statistic examines the joint hypothesis so that all the coefficients of the independent variables are 0 . Here, the Wald test is argued as a Chi squared test where the asymptotic sampling distribution is acknowledged. The $\chi^{2}(30)$ test for the ordered probit model is 224.14 , demonstrating that the joint test of all slope coefficients equating zero is rejected. Therefore, the model is statistically significant in elucidating the link between happiness and consumption. Notably, the pseudo $R^{2}$ lies between zero and one, with higher values denoting greater explanatory power and goodness of fit (Peel et al. 1998). However, the relatively low pseudo $R^{2}$ of 0.1279 reveals that a comparatively wide proportion of the variation in consumer happiness stages in the current sample is not entirely explained by the stated models. Aligned with several previous studies, this would signal that presumably other important relevant independent variables have been precluded from the analysis.

The coefficient of Age is statistically insignificant at conventional levels. Using an ordered logit model to analyze the relationships of leisure time, leisure activities and demographical factors with happiness in China, Wei et al (2015) study demonstrates an insignificant impact of age on happiness. In the same fashion, it is not ageing which upshots in exacerbating or attenuating happiness but rather the circumstances related to age. In similar fashion, the variable Female is also found insignificant relative to Male. So no impact of gender is unraveled. This is substantiated by the results of Hayo and Seifert (2003), designating that economic considerations may barely influence gender differences.

Further investigations expose Educational Attainment to be a significant stepping stone contributing happiness, with exception of the Others dummy variable across all approaches. It has been observed that relative to primary education, secondary, diploma and tertiary studies increase the probability of being happy. This is mainly engendered by the free access to education and transport to students at national level, implying that those people hoarding these advantages would secure their future in terms of income and standard of living.

Differences in happiness attitudes in both rural and urban regions tend to manifest. Living in urban regions leads to happier individuals. Prior studies, such as those steered by 
Table 3 Summary statistics of all variables used in the 2016 survey

\begin{tabular}{|c|c|c|c|c|}
\hline Variable & Mean & SD & Minimum & Maximum \\
\hline \multicolumn{5}{|l|}{ Dependent variable } \\
\hline Happiness & 2.35665 & 0.6350174 & 1 & 3 \\
\hline Independent variables & 35.39409 & 11.53489 & 18 & 67 \\
\hline \multicolumn{5}{|l|}{ Age } \\
\hline \multicolumn{5}{|l|}{ Gender } \\
\hline Male & 0.5123153 & 0.5000947 & 0 & 1 \\
\hline Female & 0.4876847 & 0.5000947 & 0 & 1 \\
\hline \multicolumn{5}{|l|}{ Educational attainment } \\
\hline Primary & 0.0866995 & 0.2815329 & 0 & 1 \\
\hline Secondary & 0.3083744 & 0.4620497 & 0 & 1 \\
\hline Diploma & 0.1211823 & 0.3264998 & 0 & 1 \\
\hline Undergraduate & 0.2985222 & 0.4578353 & 0 & 1 \\
\hline Others & 0.1852217 & 0.3886688 & 0 & 1 \\
\hline \multicolumn{5}{|l|}{ Residential location } \\
\hline Urban & 0.3438424 & 0.4752234 & 0 & 1 \\
\hline Rural & 0.6561576 & 0.4752234 & 0 & 1 \\
\hline \multicolumn{5}{|l|}{ Monthly income level } \\
\hline Level 1: below 10,000 & 0.1773399 & 0.3821444 & 0 & 1 \\
\hline Level 2: Rs. $10,001-$ Rs. 20,000 & 0.4285714 & 0.4951156 & 0 & 1 \\
\hline Level 3: Rs. $20,001-$ Rs. 30,000 & 0.1743842 & 0.3796266 & 0 & 1 \\
\hline Level 4: above Rs. 30,000 & 0.2197044 & 0.4142505 & 0 & 1 \\
\hline Family size & 4.078818 & 1.247362 & 1 & 12 \\
\hline \multicolumn{5}{|l|}{ Civil status } \\
\hline Single & 0.3763547 & 0.4847095 & 0 & 1 \\
\hline Married & 0.5694581 & 0.4953962 & 0 & 1 \\
\hline Divorced & 0.0236453 & 0.1520164 & 0 & 1 \\
\hline Others & 0.0305419 & 0.1721577 & 0 & 1 \\
\hline \multicolumn{5}{|l|}{ Social aspects } \\
\hline Social comparison & 2.278325 & 0.9276719 & 1 & 5 \\
\hline Social positioning & 3.274877 & 0.7568291 & 1 & 5 \\
\hline \multicolumn{5}{|l|}{ Basic needs indicators } \\
\hline Household expenditure & 11809.85 & 7309.853 & 1000 & 75000 \\
\hline Total expenditure & $1.21 \mathrm{E}+07$ & 0 & $1.21 \mathrm{E}+07$ & $1.21 \mathrm{E}+07$ \\
\hline Average expenditure & 12088.56 & 0 & 12088.56 & 12088.56 \\
\hline Relative expenditure & -278.705 & 7309.853 & -11088.56 & 62911.44 \\
\hline Intermediate needs deprivation index & 0.179064 & 0.1229571 & 0 & 0.75 \\
\hline \multicolumn{5}{|l|}{ Luxury consumption and other motives } \\
\hline Aesthetic appeal & 3.388177 & 1.084705 & 1 & 5 \\
\hline Brand consciousness & 2.682759 & 1.21782 & 1 & 5 \\
\hline Fashion innovativeness & 2.872906 & 1.085408 & 1 & 5 \\
\hline Commercial interest & 2.793103 & 1.123776 & 1 & 5 \\
\hline Shopping enjoyment & 2.549754 & 1.282271 & 1 & 5 \\
\hline Hedonism & 3.00936 & 0.9445479 & 1 & 5 \\
\hline Bandwagon effect & 2.24335 & 1.119529 & 1 & 5 \\
\hline
\end{tabular}


Table 3 (continued)

\begin{tabular}{llllc}
\hline Variable & Mean & SD & Minimum & Maximum \\
\hline Personality traits & & & & \\
Extraversion & 3.494253 & 0.6667857 & 1 & 5 \\
Conscientiousness & 4.040394 & 0.6950007 & 1 & 5 \\
Neuroticism & 2.835796 & 0.9354404 & 1 & 5 \\
Openness & 2.900493 & 0.7305479 & 1 & 5 \\
Agreeableness & 3.815107 & 0.7305604 & 1 & 5 \\
\hline
\end{tabular}

Wei et al. (2015), reported that urbanites appeared happier than their counterparts due to fast urbanization of China recently. This is explained by the fact that normally, one would expect to be financially better-off to pay for higher housing accommodation and tax considerations in an urban context. Concomitantly, the financial status of urbanites, integrated with their elevated means to acquire higher education makes them slightly better off than rural residents. Regardless of the size of the country, disparities in terms of providing public and private services and facilities such as health care, education, entertainment, banking and financing between urban and rural regions still persist.

Referring to the Income dummies, they tend to be insignificant, though positive, at higher brackets (e.g. Between Rs. 20,001 and Rs. 30,000). However, relative to the highest income bracket i.e. those earning more than Rs. 30,000, earning below Rs. 10,000 and between Rs. 10,001 and Rs. 20,000 reduces the probability of happiness. Correspondingly, Wang et al. (2015) suggest that if an individual has reached an optimum point in the income distribution, consumption may not induce happiness. Further justifications can be backed by Maslow's (1970) classical theory which promulgates that higher values like esteem and self-respect become prominent after lower-strata values such as basic needs have been vanquished. This paradox also resembles to that of Easterlin (2003) who enlightens that the economic well-being of a society does not translate into absolute happiness as individuals compare themselves to their counterparts. Societal influences may be at play in terms of insecurity, loss of social expectations or a plummeting confidence in the current state of affairs, thereby counteracting the benefits of higher income over time. The fact that an overwhelming proportion of the Mauritian community is ensnared in the lower income base, albeit benefitting from the exemption of income taxes at the standard rate of $15 \%$, negative happiness associations is reported.

Contrary to earlier findings, the impact of Family Size on happiness is significant but negative. As a family grows, the financial and economic burden of the head of the household takes a leap forward too since income has to be spread with extra members (Van Praag and Frijters 1999). The current trend follows that people opt for a smaller family to cushion higher household costs. In broad-spectrum, the impact of being Married relative to Single is statistically insignificant. More plausibly, this is explained partly because married couples often sketch larger-than-life plans such as child-bearing, the need to undertake personal housing, car loans, higher education loans and insurance for life or car. In the midst of this whole process, the quality of sustaining a marriage is affected and the economic situation of the survey respondent does not enhance, thereby leaving no room for happiness. This is supported by the findings of Hayo and Seifert (2003). Contrary to other studies in developing countries like Thailand (Guillen-Royo et al. 2013a, b), where marriage fuels material and psychological happiness, it is not the case in the Mauritian community which could be triggered by the sample bias because around $57 \%$ of respondents are married. 


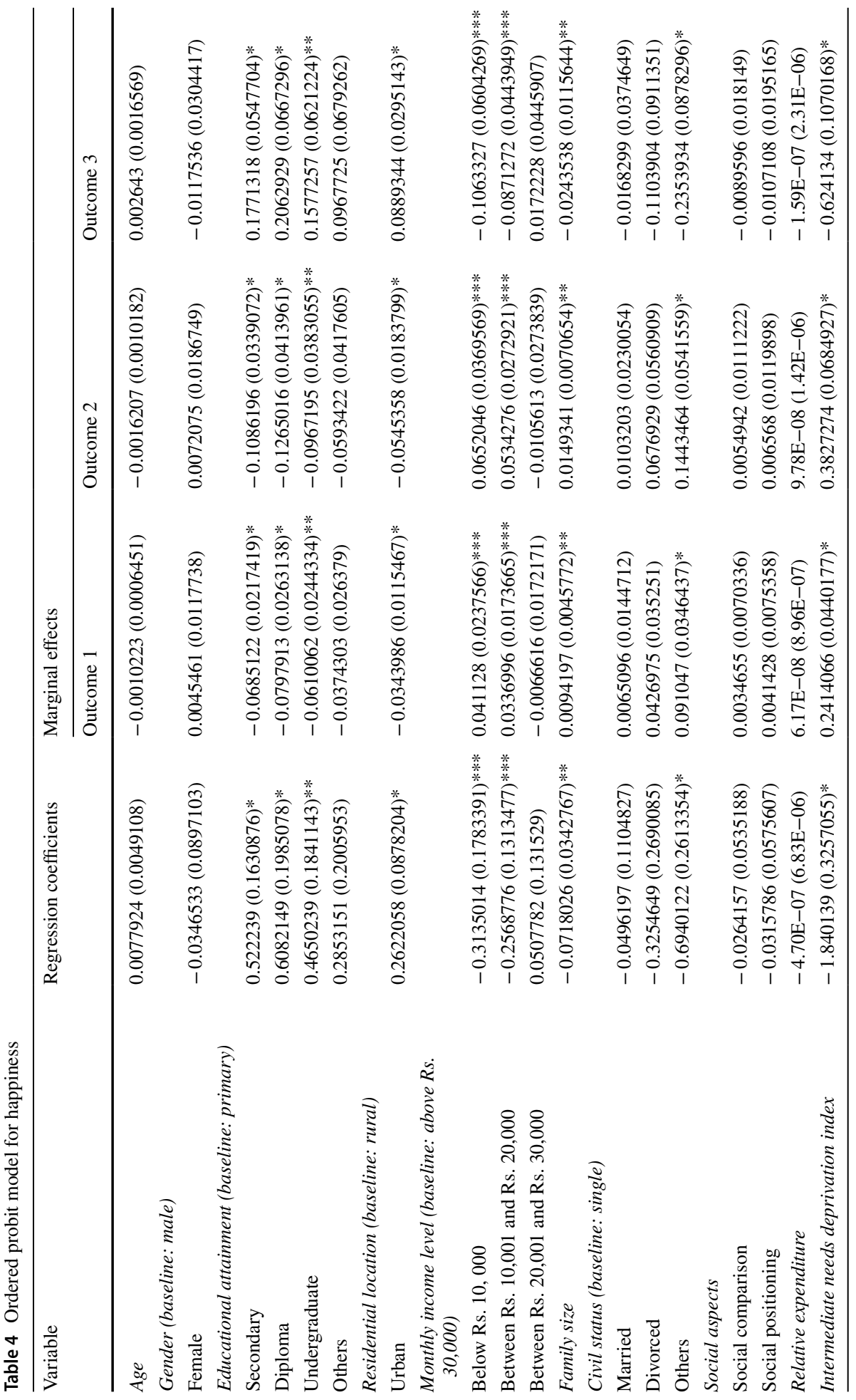




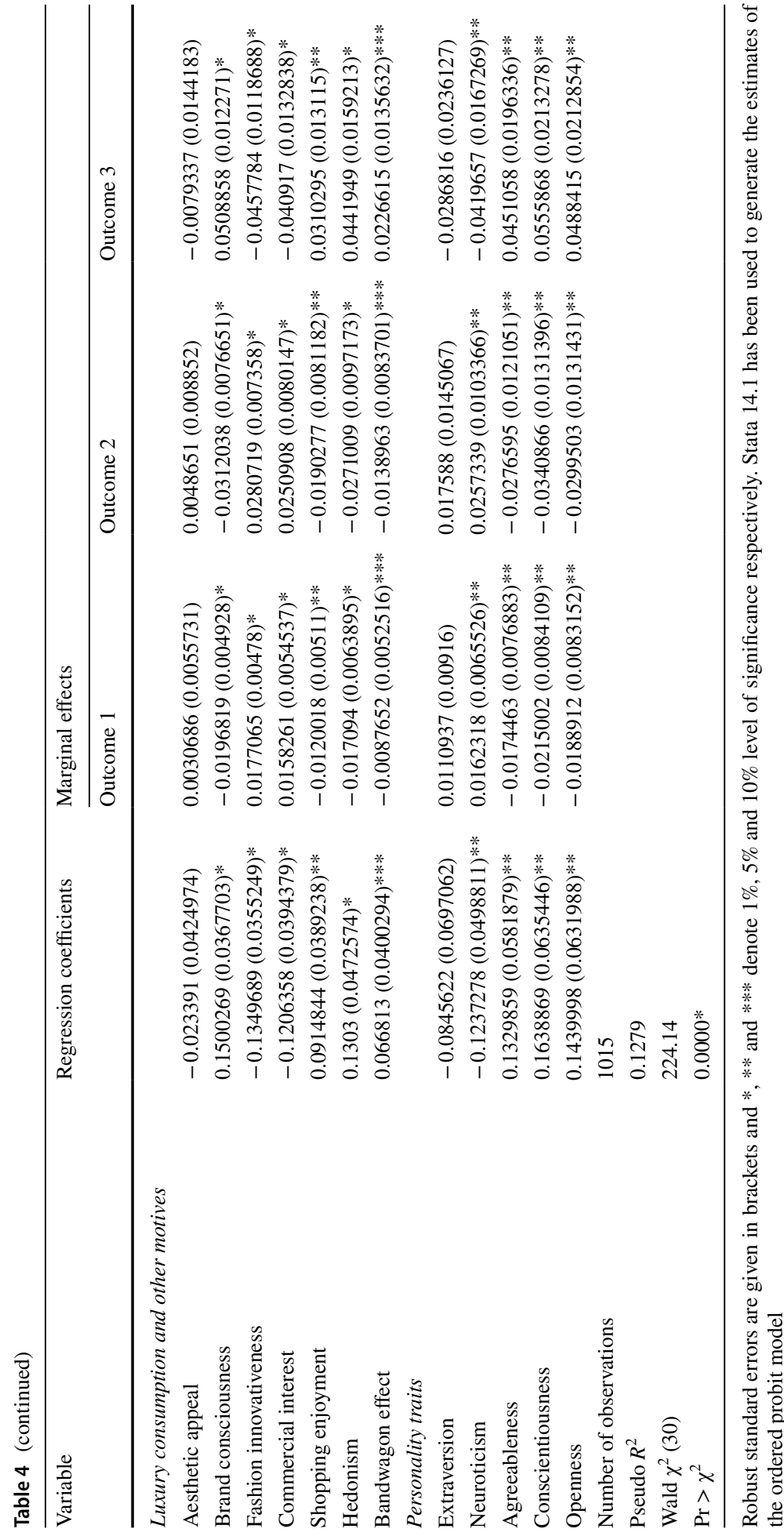


Additionally, Divorced dummy variable is found to be statistically insignificant. People, who are widowed or in cohabitation with reference to the Others dummy variable, display lower levels of happiness.

Additionally the variable Social Comparison appears to have no significant impact upon happiness, albeit having a negative coefficient. The recent work of Guillen-Royo et al. $(2013 \mathrm{a}, \mathrm{b})$ established that its influence can be scarcely predicted on happiness as it touches specific life aspects and social groups. Also, the findings affirm that having wealthier friends, neighbours or any other social contacts barely contributes to the happiness factor of Mauritian residents. Coupled with other determinants, Social Positioning is also found to be statistically insignificant. To exemplify the current finding, Layard (1980) suggests that although individuals strive to enhance their economic and social position, the overall outcome will not diffuse status satisfaction but a rise in sacrifice.

Simultaneously, Mauritius is a country of mixed cultures and social backgrounds, over time, these perceived social inequalities and stratification systems cannot withstand. Closely related, Relative Expenditure is as well uncovered to have insignificant impact on happiness. By spending more on certain goods to catch up with others does not enhance utility if people work more and forego their leisure time (Dutt 2008). A further fine-tuning of the measurement of the "monthly household expenditure" should however adjudge significant results (Guillen-Royo and Velazco 2006)

In relation to luxury consumption, Aesthetic Appeal has no impact on consumers' happiness. Despite its appeal to avant-gardism and modernity, the mall is a stationary place. With the mushrooming of mall across the island, the mall is representative of a "collective dream" which links the notion of happiness and community to that of material consumerism: from food courts, alluring cafes, cinemas to branded shops (Pusca 2009). However, the average Mauritian has not yet imbibed the whole notion of capitalism well and still relies on nearby retail shops and supermarkets to buy the needful. High prices that often do not reflect the importance of certain products displayed deter people from consuming more. Its insignificance on happiness also explains the truism that material happiness is pure illusion created for the modest consumer. Contrary to expectation, Brand Consciousness increases the probability of being happy. It may be that the consumer propensity for impulsive buying of branded products is fueled by the confidence that it can be followed by a positive mood change (Amos et al. 2014) and can lessen distress (Sneath et al. 2009). This illustrates the importance to which Mauritians attached social and symbolic values to expensive and well-known brand names in their pursuit of happiness. In spite of showing strong statistical significance, Fashion Innovativeness is negatively related to happiness. This provides insight that the Mauritian market for international fashion products may not be abreast with the world market. Also, fashion marketers may not have the proper resources to channel the goods, thus failing to bridge the gap between consumers' demand and supply. Since fashionable products involve higher income and riskier attitude, it is more likely that the local population would relent from making expensive purchases, particular those from lower and middle income base (Zhang and Kim 2012). A higher penchant for fashionable products denotes drying up of one's savings in the long run, hence reporting a negative association. Commercial Interest has the expected negative impact on happiness. It decreases the probability of being very happy by $4 \%$. Most of customers have limited budget for spending in goods, so they will buy and consume mainly based on their interest which may not be fully fulfilled. Shopping Enjoyment increases the probability of being happy. Happy shoppers may buy themselves gifts to maintain their positive feeling (Kemp and Koop 2011). Indeed, following the computed marginal effects shopping enjoyment increases the probability of being very happy by $3.1 \%$. So the overall experience 
adds positively to happiness. Hedonic consumption implies the joy and pleasure of the consumer from shopping. The variable Hedonism exerts a positive influence on the probability to be happy. It could be that it is more experimental purchases that make happier than materials ones (Van Boven and Gilovich 2003). Kacen (1994) argues that the pleasure form shopping may distract consumers from their negative feelings and provide a happier and positive focus. Indeed, Mauritians customers tend to lay greater emphasis on leisure and entertaining events (Juwaheer et al. 2013). Bandwagon Effect variable has a 10\% statistical significant and positive impact on the probability of being happy. Mauritius is moving from an upper-middle income to high-income country. ${ }^{2}$ As such, the luxury market has expanding due to the younger population being more apt to demand popular and trendy products. This reflects the social phenomenon of the "new rich" (Tomba 2004).

Four out of the five personality traits are found to have a significant impact on happiness. Extravert people enjoy interacting with others and exhibit signs of being assertive, gregarious, socially dynamic and thrill-seeking. They are also inclined towards creative affinities (Carlo et al. 2005; Hyunhee and Hyung 2015). The Extraversion variable is the only one which does not disclose any statistically significant differences. Presumably this stemmed from the fact that either the targeted questions of the variable did not represent extraversion well or the latter does not project a predominantly significant impact on happiness in Mauritius. This result is consistent to that of Zimmerman (1999) who finds no significant positive correlation between extraversion and SWB among university faculty. While speaking of Neuroticism, particular reference is made to those people who tend to be apprehensive, self-conscious, awkward, moody, touchy and impulsive. An astute point is that neurotic people tend to generate negative feelings, pessimism, guilt and depression. Due to emotional instability, they cannot muddle through their stress. This explains why such people may not be very happy, denoting a negative and significant impact of neuroticism on happiness in the results (Hyunhee and Hyung 2015; Momeni et al. 2010). As already discussed, Agreeableness generally pertains to altruism, compassion, empathy and consideration for others. Strongly allied to positive effect, it also characterises those people who value, respect and appreciate relationships or those are humble, compliant, tender and morally decent (Hyunhee and Hyung 2015). According to Costa and McCrae (1992), agreeableness is at odds with self-centred antagonism. This may reflect that being agreeableness increases the probability of being happier. Turning to the domain of Conscientiousness variable which characterises persons who work hard and showcase their degrees of organisation, reliability and voluminous priorities, it is reported in the present study that it significantly increases the probability of individuals' happiness as hypothesized by the literature (Momeni et al. 2010). For instance, conscientious individuals set commitments to accomplishing duties and goals in terms of providing basic needs to the family and expenditure on luxury goods to strike equilibrium. Finally, openness to experience refers to the elements of curiosity and receptiveness to newfound ideas and feelings. Those people are utterly imaginative or can embrace new waves of opinions and perspectives as they experience excitement with heightened form of arousal (Aluja et al. 2003; Hyunhee and Hyung 2015). In out case, a higher dimension of openness will trigger higher probability of happiness which is in line with the tabulated results.

${ }^{2}$ Online at: https://www.ocorian.com/article/mauritius-africas-investment-hub. 


\section{Conclusion}

This paper explores how socio-demographic, economic factors, luxury motives and other forms of behaviour and personality of the average Mauritian consumer are associated to the idiosyncratic happiness. Cross-sectional micro-data sieved from a group-administered survey with a sample size of around 1015 participation has been employed to analyze the varying degrees of happiness. It is to bear in mind that this model makes strong assumptions about the nature of happiness. The findings uncover that educational attainment, residential location, family size, income, the intermediate needs deprivation index, brand consciousness, fashion innovativeness, commercial interest, shopping enjoyment, hedonism, bandwagon effect, coupled with personality traits are important factors in shaping an individuals' happiness. Age, gender, social comparison, social positioning, relative income and aesthetic appeal are found to have no statistical impact on happiness.

Perhaps a pivotal finding of happiness research is that further increases in income of high-income earners will not exacerbate their level of happiness as such. This would suggest to the various policymakers, including public and private, to provide other incentives such as more holiday breaks to enjoy hedonic experiences and to alleviate their stress levels. In fact accumulating wealth can be counterproductive for happiness. From a pragmatic standpoint, it seems that hedonistic experiences contribute towards higher level of happiness. Since increasing amounts of consumption are viewed as caveats to ecological menace, policymakers could design ways to channel consumers towards a more pleasurable but less consumption-adapted lifestyle.

Having reached so far, the impacts interpreted in the preceding chapter are useful in supplementing and providing policies insight in the limited field of consumer behaviour in relation to happiness. One of the stirring aspects of happiness study is that it offers empirical evidence about actions that contribute in making people happier. The policy-maker wants to unfurl is how large an effect each variable has on happiness. The Intermediate Needs Deprivation Index has cast new light upon the basic needs level of Mauritian residents. Despite its strong negative association with happiness, a small portion of consumers are being deprived of the basic needs. Numerous policy instruments have the potential to curtail relative deprivation and to help people escape social marginalization. Governmentsponsored activities, redistributive policies or psychological support may help to mitigate relative deprivation and instill happiness in individuals. However, the downside of this action would be to sieve bring social embarrassment to those of low status.

Understanding the role of luxury consumption, via brand consciousness, fashion innovativeness, shopping enjoyment, hedonism and the bandwagon effect in positively influencing happiness, can help managers and researchers to develop a conceptual framework to analyze the main determinants affecting consumers. The managers for instance can leverage these determinants in developing brand loyalty for more profitability. A strategic finding revealed the significant negative link between commercial interest and happiness. Firms do influence consumption through their advertising and marketing techniques. From a macroeconomic perspective, higher levels consumption and production swell the GNP of the economy. However, at the micro level policymakers need to take into account that advertisement-driven consumption will make consumers worse off. For instance, public policies should aim at curtailing or banning the advertisement of those products which are harmful to the public at large, for example tobacco and alcohol. Aggressive advertisement should be discouraged to trigger general happiness. Conscious consumers tend to be happier than impulsive or automatic consumers. 
Out of five, four important personality traits are found to be related to consumer's happiness. These findings are crucial as they associate a link between consumer behaviour and personality. Individuals showcasing high agreeableness, conscientiousness and openness report elevated happiness whereas neurotic people are prone to less happiness. Extraversion has no impact on happiness. For instance, conscientiousness is the strongest Big-Five predictor of happiness and is intrinsically related to trait self-control (TSC). The greater TSC a person has, the more focus he would have on aspirations (Cheung et al. 2014). This implies that social policymakers should realize the existence of individual differences and that conscientious people are more careful and pragmatic as compared to unconscientious ones. Therefore, these policymakers need to apply an assortment of subjective and objective personality-specific measures in order to influence the level of happiness. Frequent counseling and personality appraisal with a view to identify those with high level of neuroticism can aid to implement adequate measures to uplift their spirit and boost their morale.

Acknowledgements Open access funding provided by Lulea University of Technology.

Open Access This article is distributed under the terms of the Creative Commons Attribution 4.0 International License (http://creativecommons.org/licenses/by/4.0/), which permits unrestricted use, distribution, and reproduction in any medium, provided you give appropriate credit to the original author(s) and the source, provide a link to the Creative Commons license, and indicate if changes were made.

\section{Appendix}

To construct the Relative Expenditure, total expenditure on basic needs (water, food, transport, internet, etc.) less sample average expenditure is considered. To construct the other variables, Likert-like scales are used from the questionnaire. In several cases the average of these scales are utilized. The following statements are taken from the questionnaire:

10. If your neighbour bought a luxury car (e.g. BMW), you would like to buy a better car than him.

11. You pay keen attention to what your favourite movie stars are wearing.

15. Spending on education for your children will help to enhance their position in society.

16. You can express your personality, status and individuality by buying a luxurious car.

21. Life in general.

23. Your household suffered from shortage of staple food recently.

24. Your household has no electricity or gas facilities.

25. The household drinking water is obtained from unsafe sources (e.g. not piped or bottled).

26. The household does not have access to adequate toilet facilities.

27. Any household member was ill and did not seek medical care at the hospital.

28. The head of the household has not spent time with close relatives during last week.

29. The household has not been provided with contraceptives.

30. Every adult household member has completed primary school.

31. The colours and textures in store interiors must be appealing to you (e.g. Bagatelle, Caudan, etc.).

32. You are willing to pay higher prices for famous brands (e.g. Calvin Klein, Diesel, Armani, etc.). 
33. You are the last in your circle of friends to know the names of the latest new fashions.

35. You buy certain products as they are widely advertised on television, internet and billboards.

36. When you feel moody, shopping is the best way to fix that.

38. You believe that occasional trips to famous celebrities' concerts are amusing.

39. You like to engage in adventurous activities or solo sports to have fun (e.g. paragliding, tyrolean, etc.).

42. You achieve a sense of belonging by purchasing similar popular products that others buy.

53. You often seek excitement, fame and money.

54. You like to communicate with people.

55. You are often cheerful and energetic.

56. You are disciplined, efficient and systematic in performing a task.

57. In general, people think that you can be trusted and dependent on.

58. You always try to complete an assignment on time.

59. You often feel being lonely and sad.

60. You tend to have rapid change in mood.

61. You find it hard to think plainly, make choices and handle stress whenever things go wrong.

62. You like to try new foreign activities.

63. If a black cat crosses your path, you will have bad luck all day.

64. You are strongly curious.

65. People think you are caring and like family gathering.

66. You like to work with other group of people.

67. Most of your acquaintances like you.

For statement 21, respondents are asked to state their level of happiness. A rating ranging from 1 to 3, where 1, 2 and 3 represent not very happy, fairly happy and very happy respectively are proposed. For statements 23-30, they are asked to tick yes or no while for all the other statements, individuals are asked to state how much they agree with the above statements. They give a rating ranging from 1 to 5, where 1, 2, 3, 4 and 5 represent strongly disagree, disagree, neutral, agree and strongly agree respectively.

Notes:

1. Happiness uses statement 21.

2. Social Comparison uses statements 10 and 11 .

3. Social Positioning uses statements 15 and 16.

4. INDI uses statements 23, 24, 25, 26, 27, 28, 29 and 30.

5. Aesthetic Appeal uses statement 31.

6. Brand Consciousness uses statement 32.

7. Fashion Innovativeness uses statement 33.

8. Commercial Interest uses statements 35 .

9. Shopping Enjoyment uses statements 36 .

10. Hedonism uses statements 38 and 39.

11. Bandwagon Effect uses statement 42 .

12. Extraversion uses statements 53, 54 and 55.

13. Neuroticism uses statements 59, 60 and 61.

14. Agreeableness uses statements 65, 66 and 67 . 
15. Conscientiousness uses statements 56, 57 and 58 .

16. Openness uses statements 62,63 and 64.

\section{References}

Ahuvia, A. C. (2008). Wealth, consumption and happiness. In A. Lewis (Ed.), The Cambridge handbook of psychology and economic behaviour (pp. 199-226). Cambridge: Cambridge University Press.

Aluja, A., Garcia, O., \& Garcia, L. F. (2003). Relationships among extraversion, openness to experience, and sensation seeking. Personality and Individual Differences, 35(3), 671-680.

Amos, C., Holmes, G. R., \& Keneson, W. C. (2014). A meta-analysis of consumer impulse buying. Journal of Retailing and Consumer Services, 21(2), 86-97.

Babbie, E. R. (1973). Survey research methods. Belmont: Wadsworth.

Borgatta, E. F. (1964). The structure of personality characteristics. Behavioral Science, 9(1), 8-17.

Borgatta, E. F. (1969). Sociological methodology 1969. San Francisco: Jossey-Bass.

Busch, M., (2008). Adam Smith and consumerism's role in happiness: Modern society re-examined, major themes in economics. Available at: http://business.uni.edu/economics/themes/Busch.pdf. Accessed 30 Apr 2016.

Caldas, S. B. (2010). The happiness-to-consumption ratio: An alternative approach in the quest for happiness. Estudios Gerenciales, 26(116), 15-35.

Campbell, C. (1998). Consumption and the rhetorics of need and want. Journal of Design History, 11(3), 235-246.

Carlo, G., Okun, M. A., Knight, G. P., \& de Guzman, M. R. T. (2005). The interplay of traits and motives on volunteering: Agreeableness, extraversion and prosocial value motivation. Personality and Individual Differences, 38(6), 1293-1305.

Cheung, T. T., Gillebaart, M., Kroese, F., \& De Ridder, D. (2014). Why are people with high self-control happier? The effect of trait self-control on happiness as mediated by regulatory focus. Frontiers in Psychology, 5, 722 .

Clark, A. E., Frijters, P., \& Shields, M. A. (2006). Income and happiness: Evidence, explanations and economic implications. Online at: https://halshs.archives-ouvertes.fr/halshs-00590436/document. Accessed 2 Apr 2018.

Costa, P., \& McCrae, R. (1992). Revised NEO personality inventory (NEO-PI-R) and NEO five-factor inventory (NEO-FFI) manual. Odessa, FL: Psychological Assessment Services.

DeLeire, T., \& Kalil, A. (2010). Does consumption buy happiness? Evidence from the United States. International Review of Economics, 57(2), 163-176.

Desai, M., \& Shah, A. (1988). An econometric approach to the measurement of poverty. Oxford Economic Papers, 40(3), 505-522.

Di Tella, R., Haisken-De New, J., \& MacCulloch, R. (2010). Happiness adaptation to income and to status in an individual panel. Journal of Economic Behavior \& Organization, 76(3), 834-852.

Di Tella, R., MacCulloch, R. J., \& Oswald, A. J. (2003). The macroeconomics of happiness. Review of Economics and Statistics, 85(4), 809-827.

Diener, E., \& Biswas-Diener, R. (2002). Will money increase subjective well-being? Social Indicators Research, 57(2), 119-169.

Digman, J. M., \& Takemoto-Chock, N. K. (1981). Factors in the natural language of personality: Re-analysis, comparison, and interpretation of six major studies. Multivariate Behavioral Research, 16(2), 149-170.

Doyal, L., \& Gough, I. (1991). A theory of human need. Macmillan International Higher: Basingstoke.

Duesenberry, J. (1949). Income, savings, and the theory of human behavior. Cambridge, MA: Harvard University Press.

Dunn, L., \& Hoegg, J. (2014). The impact of fear on emotional brand attachment. Journal of Consumer Research, 41(1), 152-168.

Dutt, A. K. (2006). Consumption and happiness: Alternative approaches, rough draft prepared for the conference on new directions in the study of happiness. Notre Dame: University of Notre Dame.

Dutt, A. K. (2008). The dependence effect, consumption and happiness: Galbraith revisited. Review of Political Economy, 20(4), 527-550. 
Easterlin, R. A. (1974). Does economic growth improve the human lot? Some empirical evidence. In P. A. David \& M. W. Reder (Eds.), Nations and households in economic growth (pp. 89-125). New York: Academic Press.

Easterlin, R. A., (2003). Explaining happiness. Proceedings of the National Academy of Sciences, 100(19), 11183. September 2003. Available at: http://ssrn.com/abstract=539282.

Endler, N. S., \& Rosenstein, A. J. (1997). Evolution of the personality construct in marketing and its applicability to contemporary personality research. Journal of Consumer Psychology, 6(1), 55-66.

Festinger, L. (1954). A theory of social comparison processes. Human Relations, 7(2), 117-140.

Frey, B. S., \& Stutzer, A. (2002). Happiness and economics. Princeton: Princeton University Press.

Gerdtham, U. G., \& Johannesson, M. (1997). The relationship between happiness, health and socio-economic factors: Results based on Swedish micro data. Group, 45, 64.

Gerdtham, U. G., Johannesson, M., Lundberg, L., \& Isacson, D. (1999). The demand for health: Results from new measures of health capital. European Journal of Political Economy, 15(3), 501-521.

Gilovich, T., Kumar, A., \& Jampol, L. (2015). A wonderful life: Experiential consumption and the pursuit of happiness. Journal of Consumer Psychology, 25(1), 152-165.

Goldberg, L. R. (1981). Language and individual differences: The search for universals in personality lexicons. Review of personality and social psychology, 2(1), 141-165.

Goldberg, L. R. (1983). The magical number five, plus or minus two: Some considerations on the dimensionality of personality descriptors. In A research seminar, Gerontology Research Center, Baltimore, $M D$.

Goldberg, L. R. (1992). The development of markers for the big-five factor structure. Psychological Assessment, 4(1), 26.

Goldsmith, R. (2016). The big five, happiness, and shopping. Journal of Retailing and Consumer Services, 31, 52-61.

Goldsmith, R. E., \& Hofacker, C. F. (1991). Measuring consumer innovativeness. Journal of the Academy of Marketing Science, 19(3), 209-221.

Guillen-Royo, M. (2007). Well-being and consumption: Towards a theoretical approach based on human need satisfaction. In L. Bruni (Ed.), Handbook on the economics of happiness (pp. 151-169). Cheltenham: Edward Elgar Publishing Ltd.

Guillen-Royo, M. (2008). Consumption and subjective wellbeing: Exploring basic needs, social comparison, social integration and hedonism in Peru. Social Indicators Research, 89(3), 535-555.

Guillen-Royo, M., Camfield, L., \& Velazco, J. (2013a). Universal and local reconciled: Exploring satisfaction with universal and local goals in Thailand and Bangladesh. Social Indicators Research. https:// doi.org/10.1007/s11205-013-0293-z.

Guillen-Royo, M., \& Velazco, J. (2006). Exploring the relationship between happiness, objective and subjective well-being: Evidence from rural Thailand. WeD working paper 16.

Guillen-Royo, M., Velazco, J., \& Camfield, L. (2013b). Basic needs and wealth as independent determinants of happiness: An illustration from Thailand. Social Indicators Research, 110(2), 517-536.

Guven, C. (2009). Weather and financial risk-taking: Is happiness the channel? Online at: https://ideas.repec .org/p/diw/diwsop/diw_sp218.html. Accessed 2 Apr 2018.

Hayo, B., \& Seifert, W. (2003). Subjective economic well-being in Eastern Europe. Journal of Economic Psychology, 24(3), 329-348.

Headey, B., Muffels, R., \& Wooden, M. (2008). Money does not buy happiness: Or does it? A reassessment based on the combined effects of wealth, income and consumption. Social Indicators Research, 87(1), $65-82$.

Helliwell, J., Layard, R., \& Sachs, J. (2012). World happiness report. New York: Earth Institute.

Hopkins, E. (2008). Inequality, happiness and relative concerns: What actually is their relationship?. Edinburgh: University of Edinburgh.

Hosein, N. Z. (2012). Measuring the purchase intention of visitors to the auto show. Journal of Management \& Marketing Research, 9, 1-17.

Husic, M., \& Cicic, M. (2009). Luxury consumption factors. Journal of Fashion Marketing and Management: An International Journal, 13(2), 231-245.

Hyunhee, W., \& Hyung, J. A. (2015). Big five personality and different meanings of happiness of consumers. Economics and Sociology, 8(3), 145-154.

Jaunky, V. C., \& Ramchurn, B. (2014). Consumer behaviour in the scratch card market: A double-hurdle approach. International Gambling Studies, 14(1), 96-114.

John, O. P. (1989). Towards a taxonomy of personality descriptors. In D. M. Buss \& N. Cantor (Eds.), Personality psychology (pp. 261-271). New York, NY: Springer. 
Juwaheer, T. D., Pudaruth, S., \& Ramdin, P. (2013). Enhancing customer shopping experience in malls of emerging countries-The "Mauritius" experience. World Journal of Entrepreneurship, Management and Sustainable Development, 9(2/3), 178-190.

Kacen, J. J. (1994). Phenomenological insights in mood and mood-related consumer behaviors. Advances in Consumer Research, 21, 519-525.

Kamakura, W. A., \& Du Yuxing, R. (2011). How economic contractions and expansions affect expenditure patterns. Journal of Consumer Research, 39(2), 229-247.

Kanuk, L., \& Berenson, C. (1975). Mail surveys and response rates: A literature review. Journal of Marketing Research, 12(4), 440-453.

Karthikeyan, N., \& Balamurugan, T. (2012). Mobile marketing: Examining the impactof interest, individual attention, problem faced and consumer's attitude on intention to purchase. Interdisciplinary Journal of Contemporary Research in Business, 3(10), 809-821.

Kashdan, T. B., \& Breen, W. E. (2007). Materialism and diminished well-being: Experiential avoidance as a mediating mechanism. Journal of Social and Clinical Psychology, 26(5), 521-539.

Kasser, T. (2002). The high price of materialism. Massachusetts: MIT Press.

Kastanakis, M. N., \& Balabanis, G. (2014). Explaining variation in conspicuous luxury consumption: An individual differences' perspective. Journal of Business Research, 67(2014), 2147-2154.

Kemp, E., \& Kopp, S. W. (2011). Emotion regulation consumption: When feeling better is the aim. Journal of Consumer Behaviour, 10(1), 1-7.

Kenexa Research Institute. (2007). Corporate social responsibility efforts are recognised by employees. Wayne: Kenexa Research Institute.

Knight, J., \& Gunatilaka, R. (2009). Is happiness infectious? In Discussion paper series. ISSN 1471-0498.

Krueger, A. B., \& Schkade, D. A. (2008). The reliability of subjective well-being measures. Journal of Public Economics, 92, 1833-1845.

Lasch, C. (1991). The true and only heaven: Progress and its critics. New York: WW Norton \& Company.

Layard, R. (1980). Human satisfactions and public policy. The Economic Journal, 90(360), 737-750.

Lebow, V. (1955). Price competition in 1955. Journal of Retailing, 31(1), 5-10.

Leibenstein, H. (1950). Bandwagon, snob, and Veblen effects in the theory of consumers' demand. The Quarterly Journal of Economics, 64(2), 183-207.

Linssen, R., Kempen, L. V., \& Kraaykamp, G. (2010). Subjective well-being in rural India: The curse of conspicuous consumption. DOI. https://doi.org/10.1007/s11205-010-9635-2.

Maslow, A. (1943). A theory of human motivation. Psychological Review, 50, 370-396.

Maslow, A. (1970). Motivation and personality (T ed.). Nueva York: Harper \& Row.

McCrae, R. R., \& Costa, P. T. (1987). Validation of the five-factor model of personality across instruments and observers. Journal of Personality and Social Psychology, 52(1), 81.

McCrae, R. R., \& John, O. P. (1992). An introduction to the five-factor model and its applications. Journal of Personality, 60(2), 175-215.

McGregor, A., McKay, A., \& Velazco, J. (2007). Needs and resources in the investigation of wellbeing in developing countries: Evidence from Bangladesh and Peru. Journal of Economic Methodology, 14(1), 107-131.

McGregor, I., McAdams, D. P., \& Little, B. R. (2006). Personal projects, life stories, and happiness: On being true to traits. Journal of Research in Personality, 40(5), 551-572.

Meyer, B. D., \& Sullivan, J. X. (2003). Measuring the well-being of the poor using income and consumption (No. w9760). National Bureau of Economic Research.

Momeni, M., Anvari, M. R. A., Kalali, N. S., Raoofi, Z., \& Zarrineh, A. (2010). The effect of personality on happiness: A study in the University of Tehran. In Business and social science research conference.

Noll, H.-H., \& Weick, S. (2010). Subjective well-being in Germany: Evolutions, determinants and policy implications. In Happiness and social policy in Europe. Online at: https://www.diw.de/documents/ publikationen/73/diw_01.c.338505.de/diw_sp0218.pdf. Accessed 2 Apr 2018.

Noll, H.-H., \& Weick, S. (2015). Consumption expenditures and subjective well-being: Empirical evidence from Germany. International Review of Economics, 62(2), 101-119.

Oropesa, R. S. (1995). Consumer possessions, consumer passions, and subjective well-being. Sociological forum, 10(2), 215-244.

Peabody, D., \& Goldberg, L. R. (1989). The structure of phenotypic personality traits. Journal of Personality and Social Psychology, 48(1), 26-34.

Peel, M. J., Goode, M. M., \& Moutinho, L. A. (1998). Estimating consumer satisfaction: OLS versus ordered probability models. International Journal of Commerce and Management, 8(2), 75-93.

Petrunyk, I., \& Pfeifer, C. (2016). Life satisfaction in Germany after reunification: Additional insights on the pattern of convergence. Jahrbücher für Nationalökonomie und Statistik, 236(2), 217-239. 
Popescu, C., Popescu, S. F., \& Stroe, C. (2010). Consumption for the fulfillment of human life. Amfiteatru Economic, 12(28), 530-545.

Pusca, A. (2009). 'Born to shop': Malls, dream-worlds and capitalism. Journal of International Relations and Development, 12(4), 370-377.

Ryan, R. M., \& Deci, E. L. (2001). On happiness and human potentials: A review of research on hedonic and eudaimonic well-being. Annual Review of Psychology, 52(1), 141-166.

Schrock Simring, K. (2013). Age brings happiness. Scientific American Mind. Available at: www.scientific american.com/Mind. Accessed 30 Apr 2016.

Schroder, T. (2013). Sustainability in practice: A study of how reflexive agents negotiate multiple domains of consumption, enact change, and articulate visions of the 'good life'. Doctoral dissertation, The University of Manchester (United Kingdom).

Schyns, P. (2003). Income and life satisfaction: A cross-national and longitudinal study. Eburon: Delft.

Seinauskiene, B., Mascinskiene, J., \& Jucaitytè, I. (2015). The relationship of happiness, impulse buying and brand loyalty. Procedia-Social and Behavioral Sciences, 213, 687-693.

Sneath, J. Z., Lacey, R., \& Kennett-Hensel, P. A. (2009). Coping with a natural disaster: Losses, emotions, and impulsive and compulsive buying. Marketing letters, 20(1), 45-60.

Soto, C. J. (2015). Is happiness good for your personality? Concurrent and prospective relations of the big five with subjective well-being. Journal of Personality, 83(1), 45-55.

Stanca, L., \& Veenhoven, R. (2015a). Consumption and happiness: Introduction to this special issue. International Review of Economics, 62(2), 91-99.

Stanca, L., \& Veenhoven, R. (2015b). Consumption and happiness: An introduction. International Review of Economics, 62(2), 91-99.

Thomae, H. (1989). How European is personality psychology in Europe? Paper presented at the 1st European conference of psychology, Amsterdam, July 1989.

Tomba, L. (2004). Creating an urban middle class: Social engineering in Beijing. The China Journal, 51, $1-26$.

Van Boven, L., \& Gilovich, T. (2003). To do or to have? That is the question. Journal of Personality and Social Psychology, 85(6), 1193.

Van Praag, B. M. S., \& Frijters, P. (1999). The measurement and well-being: The Leyden approach. In D. Kahneman, E. Diener, \& N. Schwarz (Eds.), Well-being: The foundations of hedonic psychology. New York: Russel Sage Foundation.

Veblen, T. (1899). The theory of the Leisure class: An economic study of institutions (p. 1924). New York: B.W. Huebsch.

Wang, H., Cheng, Z., \& Smyth, R. (2015). Does consuming more make you happier? Evidence from Chinese panel data. Online at: https://pdfs.semanticscholar.org/60e5/ff52cbeb91efff52793a3388a75404 d0c52e.pdf. Accessed 2 Apr 2018.

Wei, X., Huang, S., Stodolska, M., \& Yu, Y. (2015). Leisure time, leisure activities, and happiness in China: Evidence from a national survey. Journal of Leisure Research, 47(5), 556-576.

World Happiness Report. (2018). World happiness report 2018 (No. id: 12761). Available at: https:// s3.amazonaws.com/happiness-report/2018/WHR_web.pdf. Accessed 2 Apr 2018.

Zhang, B., \& Kim, J.-H. (2012). Luxury fashion consumption in China: Factors affecting attitude and purchase intent. Journal of Retailing and Consumer Services, 20(2013), 68-79.

Zimmerman, S. L. (1999). Self-esteem, personal control, optimism, extraversion, and the subjective wellbeing of midwestern university faculty. Thesis. Online at: https://digitalcommons.andrews.edu/cgi/ viewcontent.cgi article $=2569 \&$ context=dissertations. Accessed 2 Apr 2018.

Publisher's Note Springer Nature remains neutral with regard to jurisdictional claims in published maps and institutional affiliations. 